\title{
Experimental study of gaseous detonation propagation over acoustically absorbing walls
}

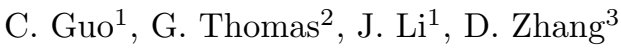 \\ 1 Department of Mechanics and Mechanical Engineering, University of Science and Technology of China, Hefei, \\ Anhui, 230026, P.R. China \\ 2 Department of Physics, University of Wales, Aberystwyth, UK \\ 3 Institute of Mechanics, Chinese Academy of Sciences, Beijing, P.R. China
}

Received 25 October 2000 / Accepted 20 August 2001

\begin{abstract}
The paper presents results from an experimental investigation of the propagation of gaseous detonation waves over tube sections lined with acoustically absorbent materials. The measurements were compared with results from control tests in a smooth wall section. The results show the increasing effectiveness of a perforated steel plate, wire mesh and steel wool in attenuating detonation.
\end{abstract}

Key words: Detonation, Propagation, Attenuation, Absorbing walls

\section{Introduction}

Early studies of gaseous detonation investigated their propagation characteristics in tubes with smooth inner walls and constant cross section. Extensive research was devoted to this subject and many important results were obtained over the early decades, see for example Manson et al. (1993). The need for a deeper understanding of the nature of detonation and requirements for increased industrial safety widened the scope of gaseous detonation research in the late 1980's. One important realization was that macroscopic detonation structure played a significant role in determining propagation behaviour, especially limit phenomena (Dupre et al. 1986). Later, interest extended to the interaction of detonation with bends and junctions as well as abrupt area expansions (Edwards et al. 1981, 1979). Another area of practical interest was the interaction of a detonation with "absorbing materials" lining the inner walls of tubes, materials which have the ability to attenuate the transverse waves associate with detonation.

Perhaps the earliest experiment on detonation and shock wave absorption was reported by Evans et al. (1955), who studied the transition to detonation in a tube lined with an acoustic damping material (porous sintered bronze) and found that the transition was delayed or even prevented. Later it was recognized that transverse waves are essential to the propagation of detonation waves and Strehlow (1969), Fowles (1984) and Edwards (1969) are amongst many who contributed to our present understanding of the microscopic nature of detonation struc-

Correspondence to: Changming Guo

(e-mail: cmguo@ustc.edu.cn) ture and the significance of the detonation 'cell'. Dupre et al. (1990) for example showed clearly how the limits of propagation of detonation in a smooth pipe could be linked to the microscopic detonation 'cell' width of mixtures. Based on this knowledge, it was then postulated that amplification of transverse waves could be delayed to a level at which self-sustained detonation wave could not form. Also, if transverse waves could be attenuated, the detonation itself would then fail.

In order to demonstrate the essential role of transverse waves Dupre et al. (1988) and Vasil'ev (1994) systematically investigated the effects of acoustic absorption on propagating detonation waves. More recently, other studies were reported by Guo and $\mathrm{Li}$ (2000). In the present work we present further results from this latter study and consider changes in the physical nature of the absorbing walls and variations in the detonation mixture composition and cellular structure characteristics.

\section{Experimental arrangement}

Experiments were performed in both circular and rectangular cross-section detonation tubes. One rectangular tube was $5.7 \mathrm{~m}$ in length with a $40 \mathrm{~mm}$ by $40 \mathrm{~mm}$ internal cross-section. The second tube was $5.5 \mathrm{~m}$ long with internal cross-section $38 \mathrm{~mm}$ by $76 \mathrm{~mm}$. Both tubes were fitted with pressure gauges whilst the second included special sections to allow smoked foil and spark schlieren studies. In the rectangular tubes the absorbent sections, lengths $463 \mathrm{~mm}$ or $820 \mathrm{~mm}$, were placed along a single wall. In the case of the $38 \mathrm{~mm}$ by $76 \mathrm{~mm}$ tube this was the narrower side, at the bottom when viewing schlieren and smoked foil images. 
Table 1. Test gas mixtures used in the present studies

$$
\begin{aligned}
& 2 \mathrm{H}_{2}+\mathrm{O}_{2} \\
& 2 \mathrm{H}_{2}+\mathrm{O}_{2}+3 \mathrm{Ar} \\
& 2 \mathrm{H}_{2}+\mathrm{O}_{2}+9 \mathrm{Ar} \\
& 2 \mathrm{H}_{2}+\mathrm{O}_{2}+4 \mathrm{~N}_{2} \\
& \mathrm{C}_{2} \mathrm{H}_{6}+7 \mathrm{O}_{2}+4.5 \mathrm{Ar} \\
& \mathrm{C}_{2} \mathrm{H}_{6}+7 \mathrm{O}_{2}+9 \mathrm{Ar} \\
& \mathrm{C}_{3} \mathrm{H}_{8}+5 \mathrm{O}_{2}+6 \mathrm{Ar}
\end{aligned}
$$

Tests were also conducted in a third cylindrical detonation tube, $5.5 \mathrm{~m}$ long with a $50 \mathrm{~mm}$ nominal bore. A special section was constructed, again nominal bore 50 $\mathrm{mm}$, to allow the solid wall to be replaced by a $6 \mathrm{~mm}$ thick layer of absorbent material. This material was contained within a perforated liner.

All of the detonation tubes were further configured to provide an initial detonation initiation section followed by a suitable length of pipe over which the detonation was stabilized before it traversed the absorbent material.

A range of absorbent materials were tested. In the 40 by $40 \mathrm{~mm}$ tube a $463 \mathrm{~mm}$ long $3 \mathrm{~mm}$ thick steel plate perforated by a matrix of $4 \mathrm{~mm}$ holes was used to line the otherwise solid wall. The distance between two adjacent hole-centers was $5 \mathrm{~mm}$ giving a plate containing 93 columns in the longitudinal and 8 rows in the transverse directions. The porosity of the perforated steel plate was $50.4 \%$.

In the $38 \mathrm{~mm}$ by $76 \mathrm{~mm}$ and $50 \mathrm{~mm}$ diameter tubes both a commercial woven wire mesh (standard mesh size 40 , nominal aperture $0.42 \mathrm{~mm}$ ) and a standard commercial 'steel wool' were used to line the tube walls. The layer thickness used was $12 \mathrm{~mm}$ in both cases. In the case of the mesh, 24 layers were used. A single layer of this mesh was also used to retain the steel wool.

The various test gas mixtures used are listed in Table 1. A range of possible mixtures was chosen, to provide a variation in the detonation cell structure. This variation is illustrated in Fig. 1 which shows spark schlieren images from stoichiometric hydrogen- and ethane-oxygen diluted with $50 \%$ argon at initial pressures of $8.0 \mathrm{kPa}$ and 10.1 $\mathrm{kPa}$ respectively. A regular transverse wave structure at the detonation front is clearly evident with the hydrogen mixture whereas ethane has a more turbulent appearance, reflecting the more irregular nature of the transverse structure in this mixture.

Pressure gauges were used on all the tubes to monitor the detonation propagation before and within the absorbent material sections. Care was taken to ensure that the distance between transducers was sufficient to observe the absorption of transverse waves and any consequential decline in detonation velocity and pressure. As a detonation wave enters a section with one wall lined with an absorbing material the transverse waves collide with the plate and a part of the transverse wave will be absorbed. This "disturbance" will propagate in the opposite direction with sonic speed and before it is reflected at the op-

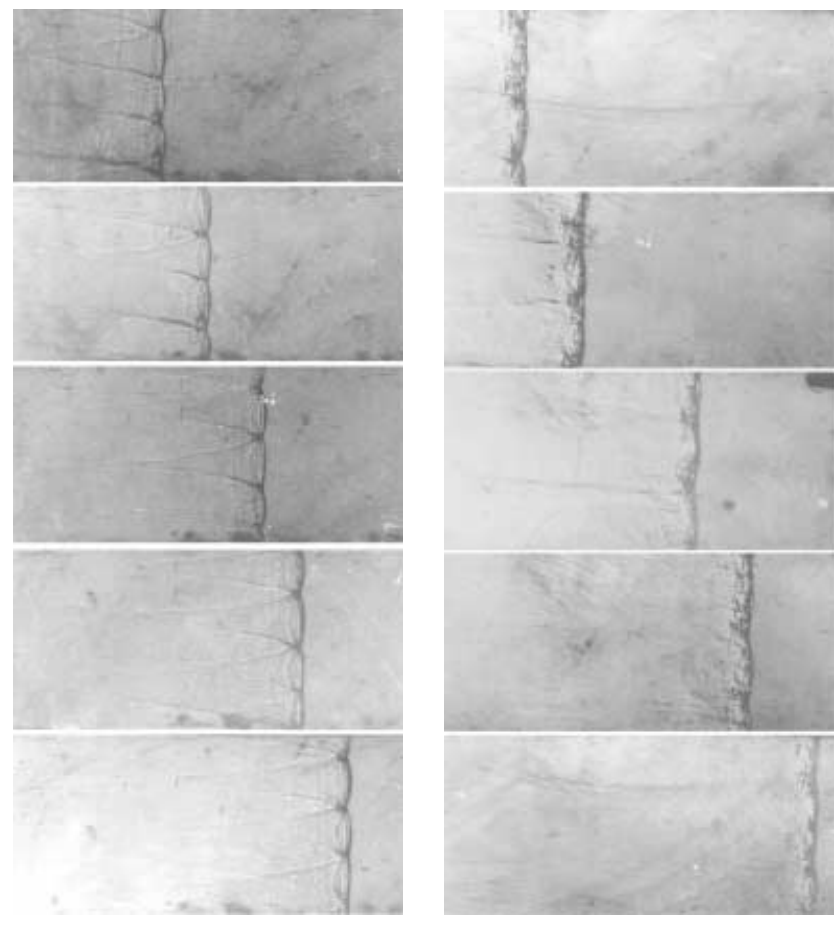

Fig. 1. Spark schlieren images of detonation propagating in a smooth tube. $2 \mathrm{H}_{2}+\mathrm{O}_{2}+3 \mathrm{AR}$, initial pressure $10.1 \mathrm{kPa}$ (left) and $\mathrm{C}_{2} \mathrm{H}_{6}+3.5 \mathrm{O}_{2}+4.5 \mathrm{Ar}$, initial pressure $8.0 \mathrm{kPa}$ (right)

posing wall. The characteristic time for the disturbance to travel across the tube width $t_{c}$ is given by

$$
t_{c}=\frac{d}{a_{c j}}
$$

where $d$ is the size of tube cross-section, $a_{c j}$ the local sonic speed in the burnt gas behind the detonation fronts. During this characteristic time the detonation will travel a distance

$$
L=D t_{c}
$$

where $D$ is the speed of detonation and $L$ a characteristic distance. Thus

$$
\frac{L}{d}=\frac{D}{a_{c j}}
$$

and for most fuel-oxygen mixtures the non-dimensionalized distance ranges between 1.82 to 1.86 . This value is halved for a circular pipe. Care was taken therefore to make measurements at least this number of tube diameters from the start of the absorbent sections. The gauge locations used in the three tubes, measured relative to the start of the absorbing section, are given in Table 2 .

\section{Results: rectangular tubes}

\subsection{Perforated plate}

These experiments were performed in the 40 by $40 \mathrm{~mm}$ tube. Detonations in undiluted hydrogen-oxygen propagated either in the smooth wall tube or over a section of 
Table 2. Location of pressure gauges in the three detonation tubes. Distances (in $\mathrm{mm}$ ) are all relative to the start of the absorbing section

\begin{tabular}{lccc}
\hline Pressure gauge & \multicolumn{3}{c}{ Position $(\mathrm{mm})$} \\
\hline Gauge & $40 \times 40 \mathrm{~mm}$ & $38 \times 76 \mathrm{~mm}$ & $50 \mathrm{~mm}$ \\
\hline P1 & 0 & -1275 & -276 \\
P2 & 125 & -275 & -76 \\
P3 & 175 & 610 & 254 \\
P4 & 417 & 685 & 397 \\
P5 & & & 500 \\
\hline
\end{tabular}

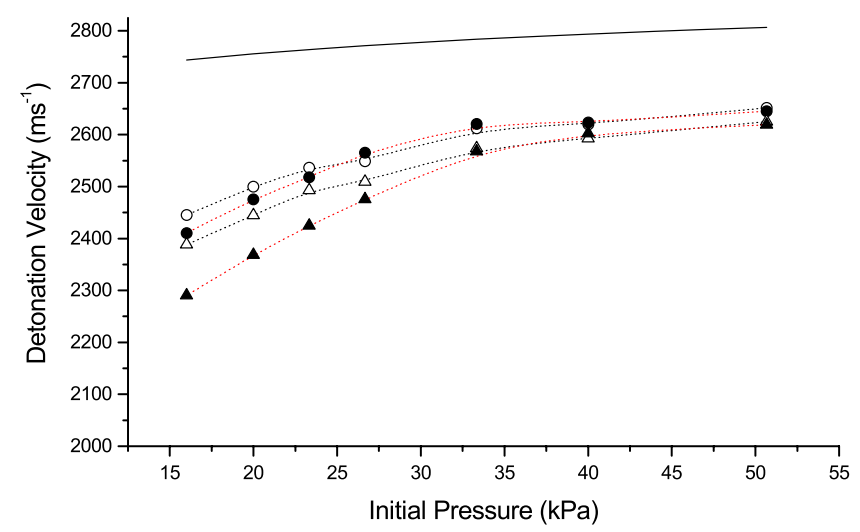

Fig. 2. Variation in theoretical detonation velocity (solid line) as a function of initial pressure with undiluted $2 \mathrm{H}_{2}+\mathrm{O}_{2}$ and measured average velocities between pressure gauges (symbols) with: a smooth wall $\circ \mathrm{P}_{1}-\mathrm{P}_{3}$ and $\bullet \mathrm{P}_{3}-\mathrm{P}_{4}$; a perforated plate on one wall $\triangle \mathrm{P}_{1}-\mathrm{P}_{3}$ and $\boldsymbol{\Delta} \mathrm{P}_{3}-\mathrm{P}_{4}$

$3 \mathrm{~mm}$ thick perforated plate. Experimental velocities obtained using the gauges listed in Table 1 show only a small decline in measured propagation velocity over a wide range of initial pressures, see Fig. 2. Also plotted on this figure are the theoretical detonation velocities as a function of initial pressure. There is an evident velocity deficit in all of the experimental measurements, relative to the ideal theoretical values, even in the smooth tube. The introduction of a perforated plate on one wall leads to a further small decrease in measured local average velocities. Quantitatively, the magnitude of the additional deficit increased from ca. $1 \%$ at an initial pressure of $50.7 \mathrm{kPa}$ to some $5 \%$ at $16.0 \mathrm{kPa}$.

The variation in peak pressures measured as a function of distance for initial pressures of $23.3 \mathrm{kPa}, 26.7 \mathrm{kPa}$ and $50.7 \mathrm{kPa}$ are shown in Fig. 3. The different symbols on each plot are measurements from repeat tests and the solid lines are peak detonation pressures measured in the smooth tube. These again show that there is a some attenuation at the wave front as the detonation enters the section lined with the perforated plate. At the lowest pressure, see Fig. 3a, there is evidence of a pressure increase at the end of the section.
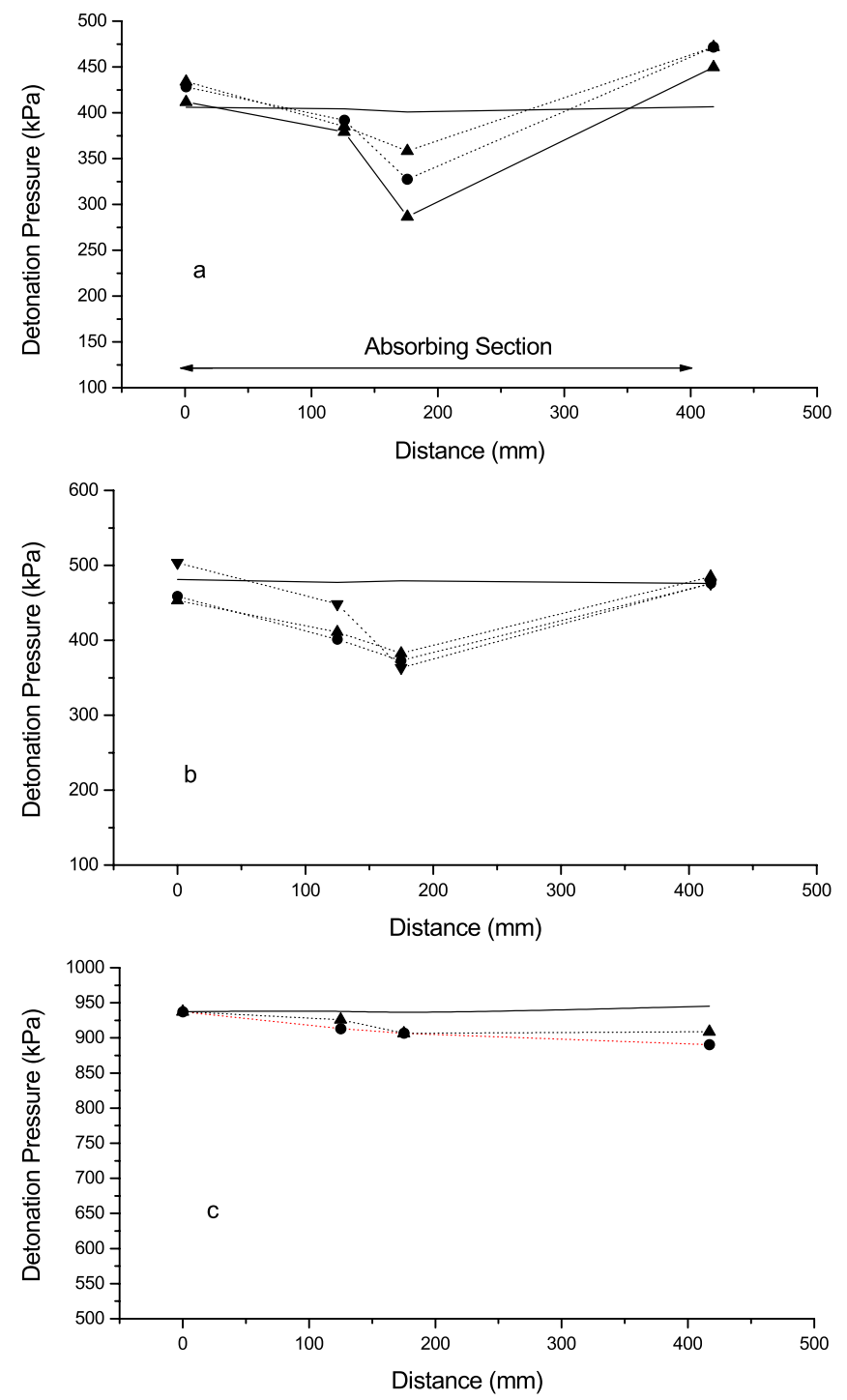

Fig. 3a-c. Measured peak detonation pressures with smooth wall (solid lines) and variation of measured peak pressure with distance in repeat tests (symbols) in the $40 \mathrm{~mm}$ by $40 \mathrm{~mm}$ tube with a perforated plate on one wall. Mixture $2 \mathrm{H}_{2}+\mathrm{O}_{2}$, initial pressures a $23.3 \mathrm{kPa}, \mathbf{b} 26.7 \mathrm{kPa}$ and $\mathbf{c} 50.7 \mathrm{kPa}$

\subsection{Wire mesh and steel wool}

Average wave velocities measured by the last two gauges at the end of the absorbing section in the $38 \mathrm{~mm}$ by $76 \mathrm{~mm}$ tube are shown in Fig. 4 for a smooth tube and with the absorbing section lined with wire mesh or steel wool. These show that there are critical limiting pressures below which rapid attenuation of the detonation occurs, at which point the leading shock and the reaction front decouple and the wave velocity decreases dramatically.

Figure 5 presents schlieren images with test mixtures $2 \mathrm{H}_{2}+\mathrm{O}_{2}+3 \mathrm{Ar}$ and $\mathrm{C}_{2} \mathrm{H}_{6}+3.5 \mathrm{O}_{2}+4.5 \mathrm{Ar}$ at initial pressures of $10.1 \mathrm{kPa}$ and $8.0 \mathrm{kPa}$ respectively. The observation window for the schlieren visualization covered the latter half of the absorbing section. Both tests were at pressures above the point at which failure was indicated 


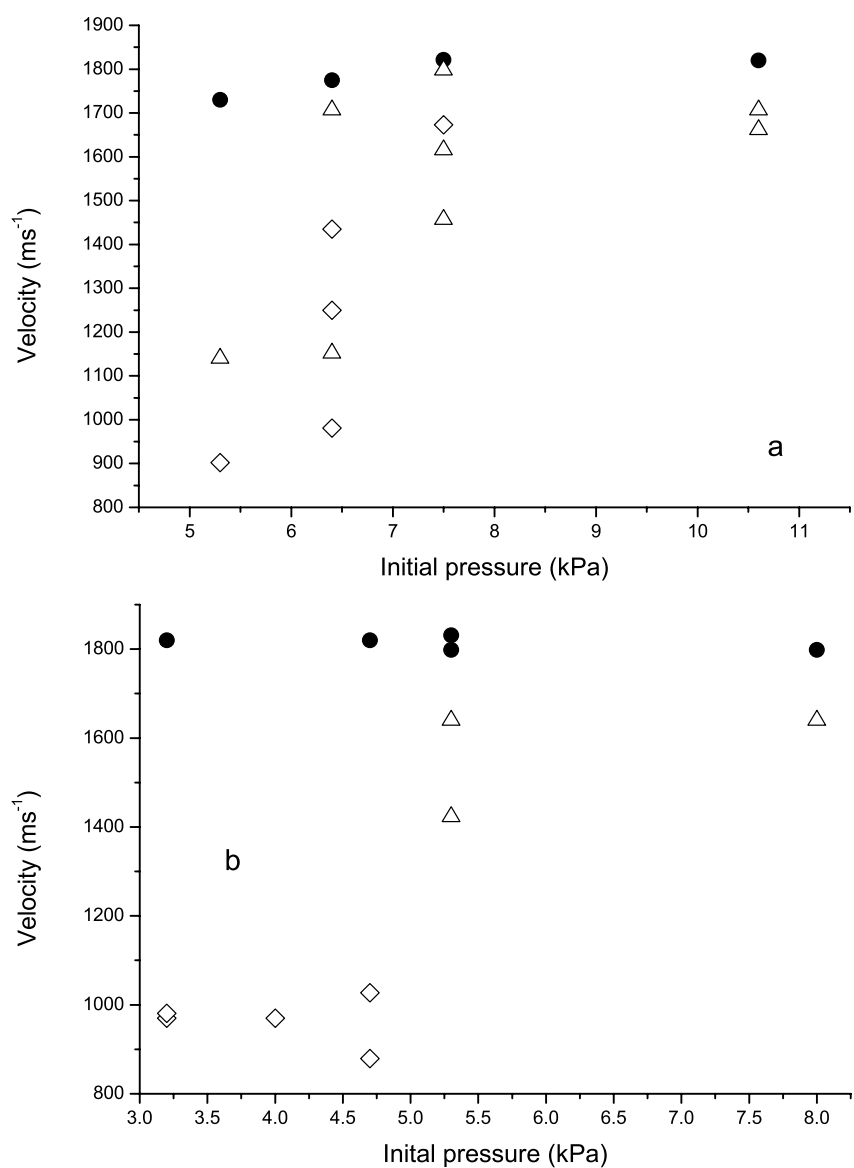

Fig. 4a,b. Variation in average velocity at end of absorbing section as a function of initial pressure in a $76 \mathrm{~mm}$ by $38 \mathrm{~mm}$ tube. $\bullet$ smooth tube, $\triangle$ one $38 \mathrm{~mm}$ wall lined with wire mesh, $\diamond$ one $38 \mathrm{~mm}$ wall lined with steel wool. Mixtures a $2 \mathrm{H}_{2}+\mathrm{O}_{2}+3 \mathrm{Ar}$ b $\mathrm{C}_{2} \mathrm{H}_{6}+3.5 \mathrm{O}_{2}+4.5 \mathrm{Ar}$

from pressure measurements of average wave front velocity, see Fig. 4. The regular hydrogen mixtures propagating over the layer of wire mesh has a general transverse wave structure whose spacing is larger than that observed in the smooth tube, see Fig. 2, whilst the irregular ethane mixture shows a deviation from macroscopic planarity near the absorbing layer of steel wool along the bottom wall.

When the initial pressure of the $\mathrm{C}_{2} \mathrm{H}_{6}+3.5 \mathrm{O}_{2}+4.5 \mathrm{Ar}$ mixture was reduced to $4 \mathrm{kPa}$ an obvious de-coupling of the lead shock and exothermic reaction was observed as it propagated over a layer of steel wool, see Fig. 6 .

The effect of an absorbing wall on transverse detonation structure can also be seen in smoked foil records presented in Fig. 7. The mixture was $2 \mathrm{H}_{2}+\mathrm{O}_{2}+3 \mathrm{Ar}$. For an initial pressures of $10.1 \mathrm{kPa}$ a general increase in detonation cell size and irregularity is seen for the test with wire mesh present, compared to the smooth wall record. When the pressure was reduced to $5.3 \mathrm{kPa}$, with steel wool lining, the cell size increased dramatically and only a single weak collision of two transverse shocks is visible towards the later half of the record. Such weak collisions are reminiscent of patterns obtained near the limit of propagation.

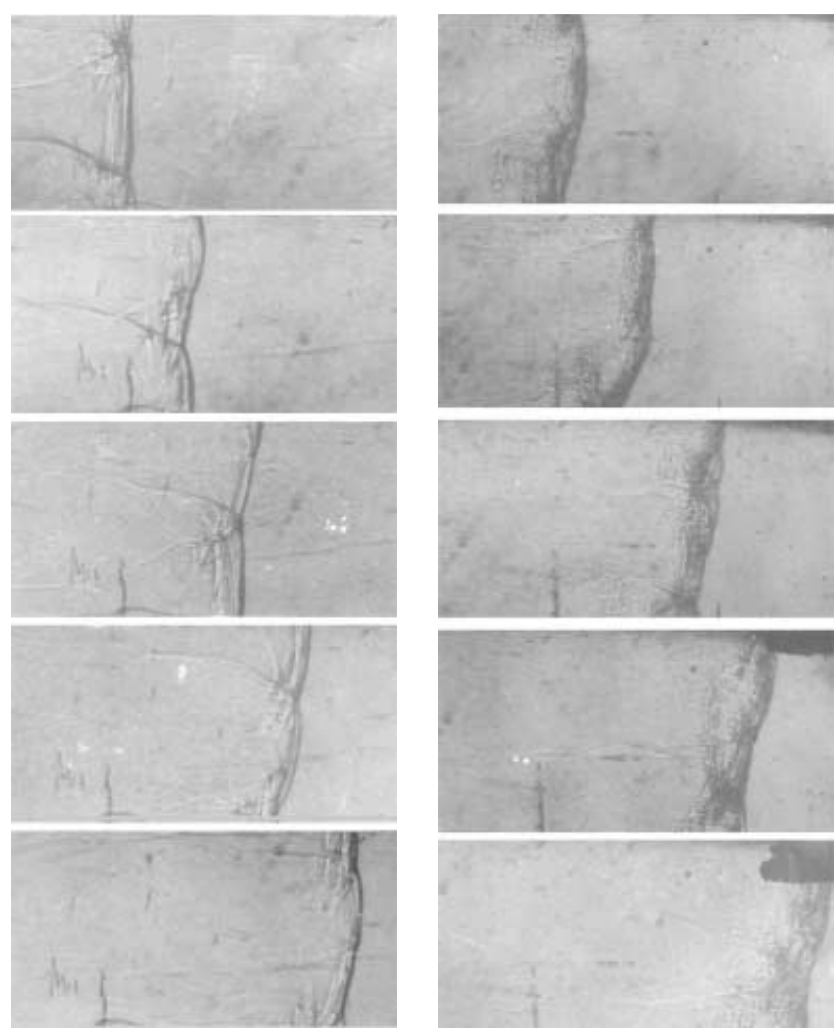

Fig. 5. Schlieren images of detonation propagating over an absorbent wall (bottom of images). $2 \mathrm{H}_{2}+\mathrm{O}_{2}+3 \mathrm{Ar} \mathrm{P}_{0} 10.1 \mathrm{kPa}$ over wire mesh (left) and $\mathrm{C}_{2} \mathrm{H}_{6}+3.5 \mathrm{O}_{2}+4.5 \mathrm{Ar} \mathrm{P}_{0} 8.0 \mathrm{kPa}$ over steel wool (right)

With the initially more irregular $\mathrm{C}_{2} \mathrm{H}_{6}+3.5 \mathrm{O}_{2}+4.5 \mathrm{Ar}$ mixture the smoked foil record obtained at $4.7 \mathrm{kPa}$ with steel wool lining, Fig. 8, showed both an increase in the larger mean cell size and an almost complete attenuation of the fine sub-structure found in the smooth wall control test.

\section{Results: circular tube}

Detonation velocities measured in the $50 \mathrm{~mm}$ diameter tube are shown in Fig. 9 for mixtures at various initial pressures with the absorbing section lined with wire mesh.

Figure 10 presents measured average velocities with the absorbing section lined with steel wool and mixtures of $2 \mathrm{H}_{2}+\mathrm{O}_{2}+9 \mathrm{Ar}$ and $\mathrm{C}_{2} \mathrm{H}_{6}+3.5 \mathrm{O}_{2}+4.5 \mathrm{Ar}$ at different initial pressures. Both the preceding figures indicate that a rapid de-coupling occurs below some critical pressure, which varies with the test mixture. These limiting pressures are listed in Table 3 for both wire mesh and steel wool.

\section{Discussion and conclusions}

For perforated plates, the contributions from wall heat and momentum losses are far greater than absorption effect 

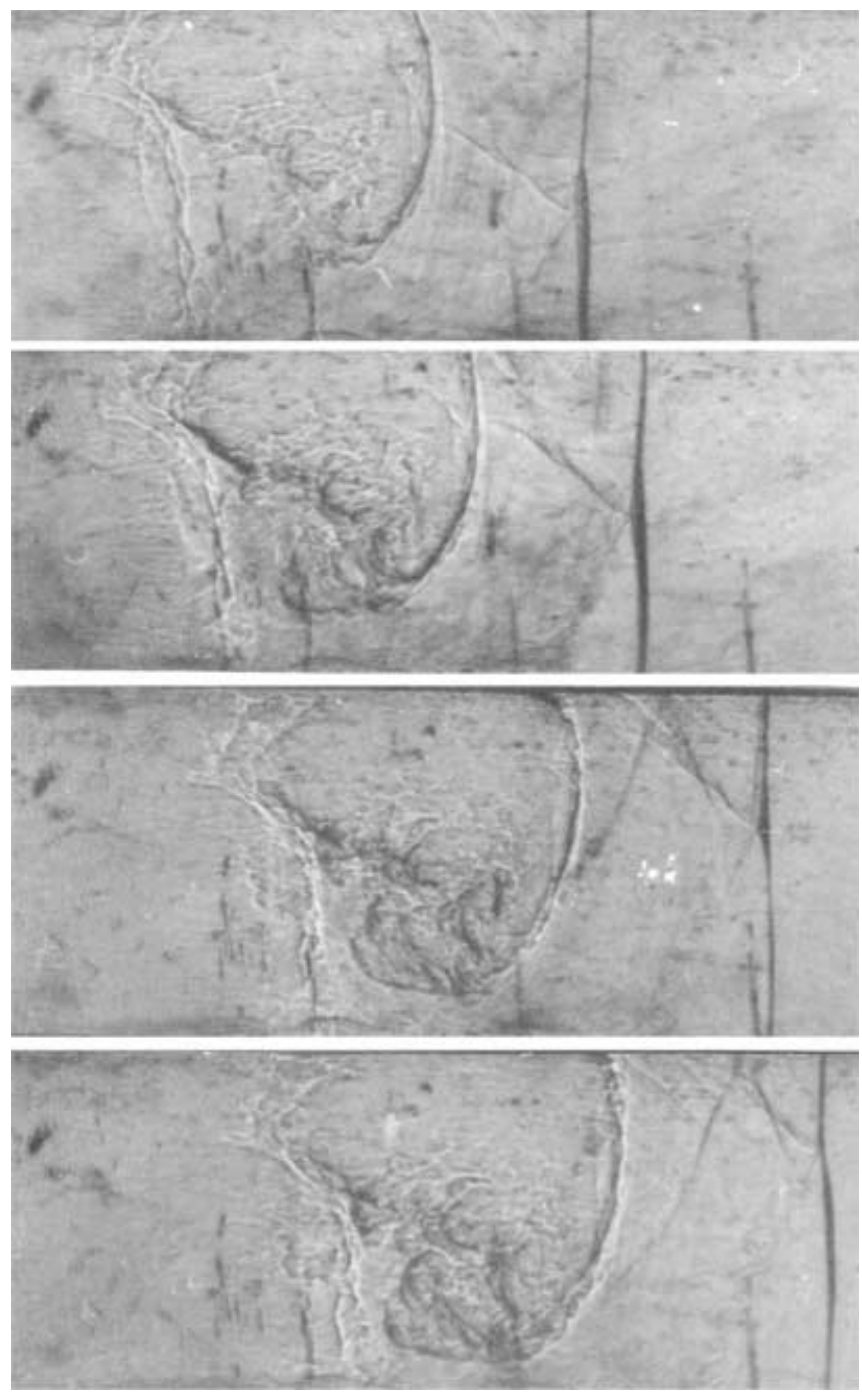

Fig. 6. Schlieren images of detonation in $\mathrm{C}_{2} \mathrm{H}_{6}+3.5 \mathrm{O}_{2}+4.5 \mathrm{Ar}$ propagating over steel wool showing a strong de-coupling between the lead shock and exothermic reaction front. Initial pressure $4 \mathrm{kPa}$

due to the change in the wall profile. Thus the additional velocity deficit is much less than the integrated effect of viscous effects at the tube walls at the pressures and tube dimensions used. There is some indication of a pressure enhancement at the end of the test section at the lowest pressures tested, ca. $4 \mathrm{kPa}$, but the extent of the deficit is not sufficient for the detonation wave to have failed. The accepted detonation cell spacing at this pressure in a large diameter tube is of the order of $5 \mathrm{~mm}$ and in the 40 by 40 $\mathrm{mm}$ tube this will have increased slightly due to boundary layer effects and associated walls losses. The increase in pressure observed towards the end of the perforated plate is most likely due to the increased separation of the lead shock and reaction zone as the wave decelerates, allowing the pressure gauge to better resolve the von Neumann zone of compressed unreacted gas at the head of the detonation front.
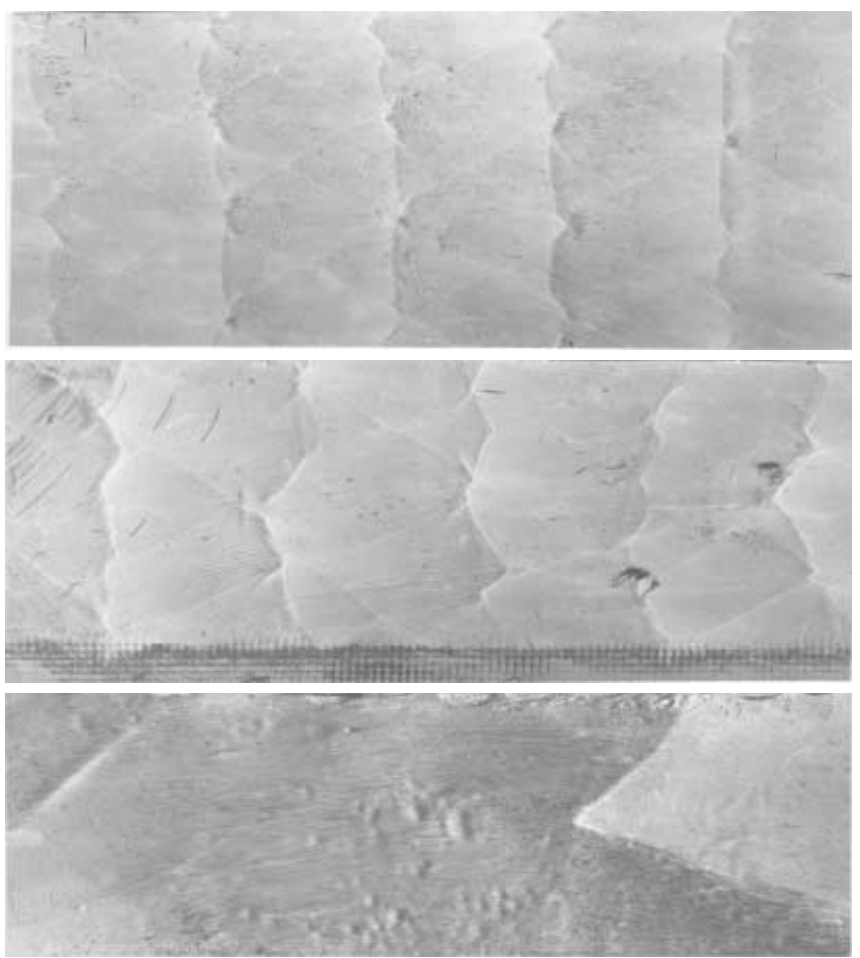

Fig. 7. Smoked foil records with $2 \mathrm{H}_{2}+\mathrm{O}_{2}+3 \mathrm{Ar}$. Smooth tube (upper) $\mathrm{P}_{0} 10.1 \mathrm{kPa}$, wire mesh (middle) $\mathrm{P}_{0} 10.1 \mathrm{kPa}$ and steel wool (lower) $\mathrm{P}_{0} 5.1 \mathrm{kPa}$. Propagation from left to right
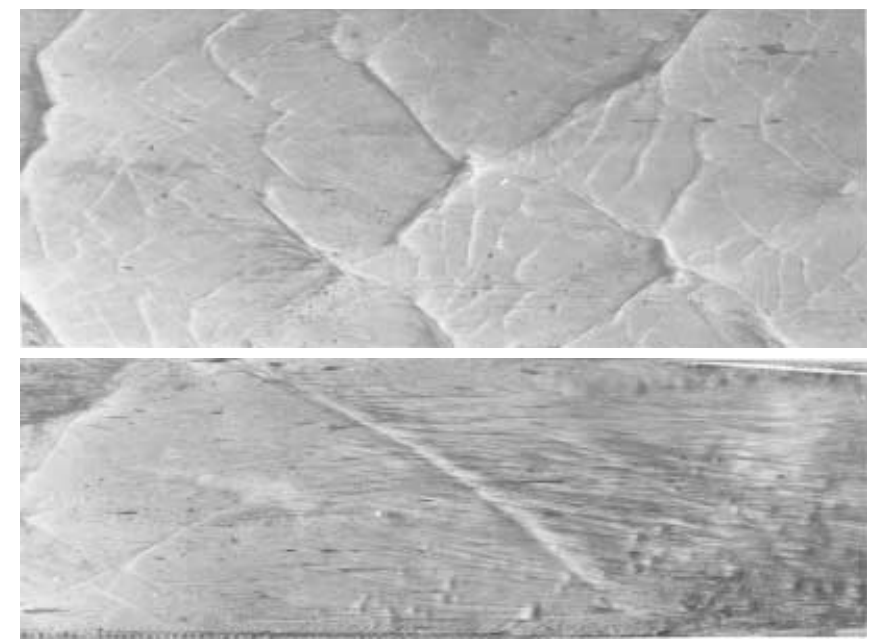

Fig. 8. Smoked foil records with $\mathrm{C}_{2} \mathrm{H}_{6}+3.5 \mathrm{O}_{2}+4.5 \mathrm{Ar}$ in a smooth tube (upper) and with the bottom wall lined with steel wool (lower). Initial pressures $5.3 \mathrm{kPa}$. Propagation from left to right

The total velocity deficit recorded in many test was often in excess of the $10 \%$ of theoretical CJ velocity, usually taken as the limiting deficit a steady wave in a smooth tube can tolerate before failing. It may be possible therefore that local shock ignition of mixture has supported the main wave, following shock reflection and diffraction effects within and around the holes that form the perforated plate. 

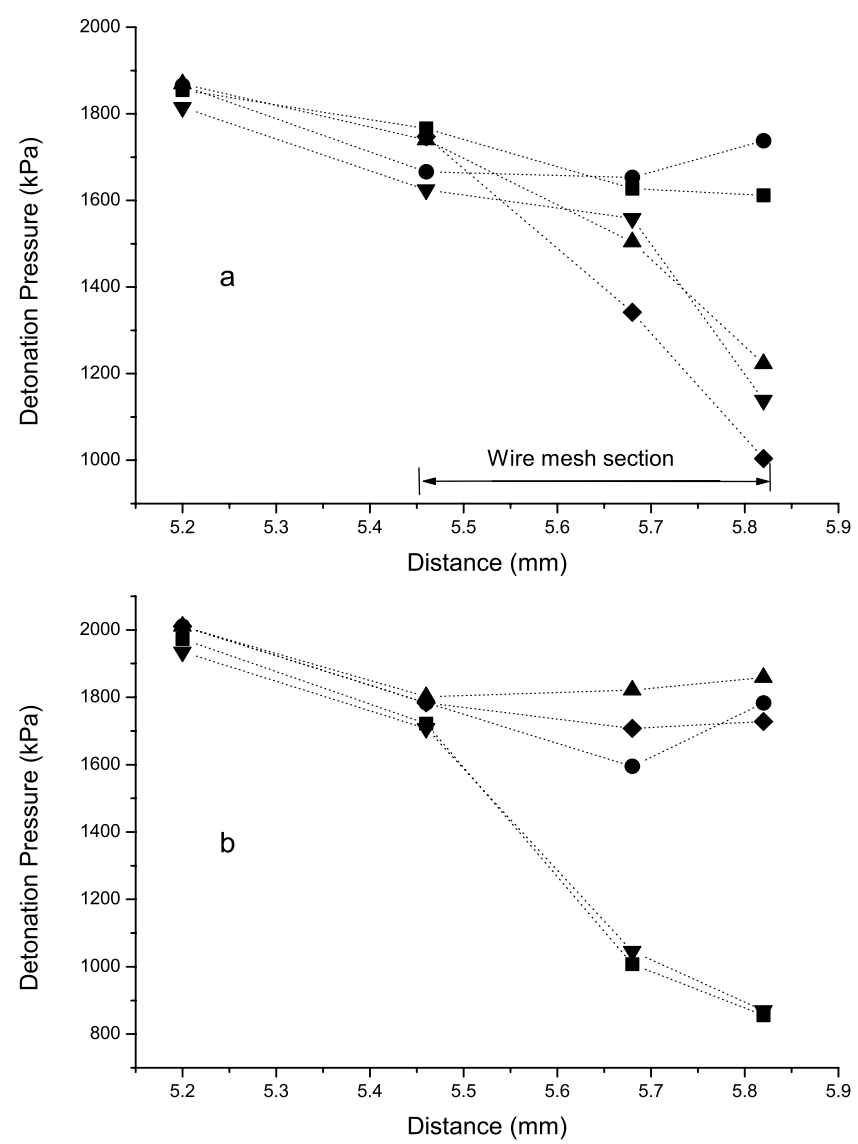

Fig. 9a,b. Measured wave velocities as a function of initial pressure along a cylindrical pipe diameter $50 \mathrm{~mm}$ lined with wire mesh. Mixtures: a $\mathrm{C}_{3} \mathrm{H}_{8}+5 \mathrm{O}_{2}+6 \mathrm{Ar}$, initial pressures - $13.3 \mathrm{kPa}, \boldsymbol{\square} 10.6 \mathrm{kPa}, \boldsymbol{\Delta} 9.3 \mathrm{kPa}, \boldsymbol{\nabla} 8.0 \mathrm{kPa} \bullet 6.7 \mathrm{kPa}$ and $\mathbf{b}$ $\mathrm{C}_{2} \mathrm{H}_{6}+3.5 \mathrm{O}_{2}+4.5 \mathrm{~N}_{2}$, initial pressures $\boldsymbol{\Delta} 26.6 \mathrm{kPa}, \bullet 23.9 \mathrm{kPa}$, $\checkmark 21.9 \mathrm{kPa}, \boldsymbol{\nabla} 21.3 \mathrm{kPa}$ and $\mathbf{\square} 17.3 \mathrm{kPa}$

The results obtained from pressure measurements in the $50 \mathrm{~mm}$ diameter tube show that both steel wool and wire mesh are equally effective in attenuating detonations. Both are also far more effective than a simple thin perforated plate. The convoluted internal structures are more effective absorbers than the diffracting and reflecting geometry provided by repeated patterns of relatively large repeated surface openings.

Not surprisingly, the efficiency of both steel wool and wire mesh increases with decreasing initial pressure, i.e. decreasing reactivity and increasing cell size. For these linings, below a critical limiting pressure, significant rapid decreases in average front velocities were observed. The observed limiting pressures in the present geometry are listed in Table 3 for the $50 \mathrm{~mm}$ diameter tube. Given the limited length of the attenuating section these cannot be considered definitive and it is likely that waves at lower intial pressures might eventually fail for longer lengths of absorbent section. The present studies do however allow the relative effectiveness of absorbing materials with different mixtures to be assessed.
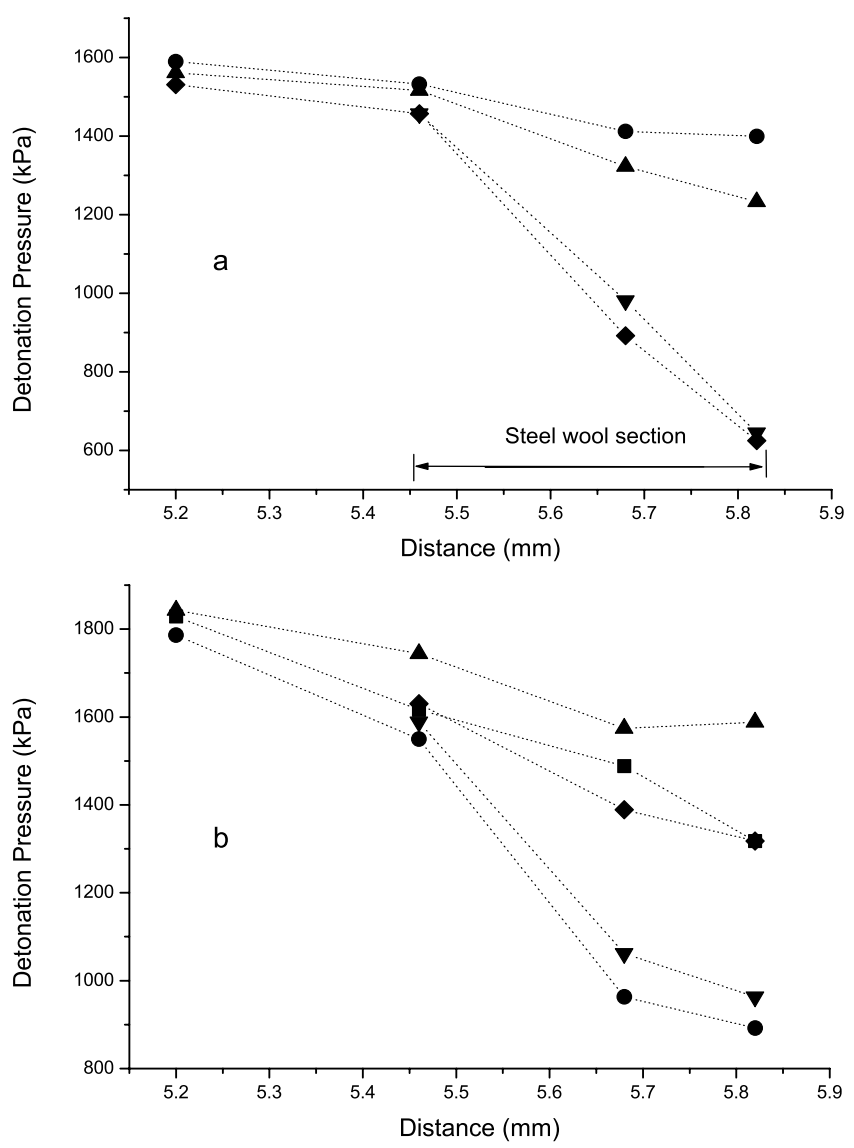

Fig. 10a,b. Measured wave velocities as a function of initial pressure along a cylindrical pipe diameter $50 \mathrm{~mm}$ lined with wire mesh. Mixtures a $2 \mathrm{H}_{2}+\mathrm{O}_{2}+9 \mathrm{Ar}$, initial pressures - $46.6 \mathrm{kPa}, \boldsymbol{\Delta} 34.6 \mathrm{kPa}, \boldsymbol{\nabla} 31.9 \mathrm{kPa} \diamond 26.6 \mathrm{kPa}$ and $\mathbf{b}$ $\mathrm{C}_{2} \mathrm{H}_{6}+3.5 \mathrm{O}_{2}+4.5 \mathrm{Ar}_{2}$, initial pressures $\boldsymbol{\Delta} 13.3 \mathrm{kPa}, \boldsymbol{} 10.6 \mathrm{kPa}$, - $9.3 \mathrm{kPa}, \boldsymbol{\nabla} 8.6 \mathrm{kPa}$ and $\bullet 5.3 \mathrm{kPa}$

The limiting pressures obtained in a rectangular tube lined along only one wall are, as expected, lower than for the circular tube. The 36 by $76 \mathrm{~mm}$ tube lined along the narrowest wall has only $17 \%$ of the perimeter composed of absorbing material compared to the $100 \%$ coverage in the cylindrical geometry. Thus for $2 \mathrm{H}_{2}+\mathrm{O}_{2}+3 \mathrm{Ar}$ the critical pressure in the cylindrical tube is ca. $12 \mathrm{kPa}$ but is less than $5 \mathrm{kPa}$ in the rectangular tube. The visualization images obtained in the rectangular geometry do however allow the influence on transverse structures to be seen quite clearly. Thus Figs. 7 and 8 illustrate how the 'natural' cell structure of a detonation is enlarged as the bottom wall is lined with an absorbent material whilst Fig. 6 demonstrates how sufficient attenuation of the wave velocity leads to a de-coupling of the shock and trailing reaction.

Table 3 indicates that both steel wool and wire mesh are equally effective in attenuating detonation and that the observed limiting pressures are roughly the same for a given mixture. For example, significant velocity deficits become apparent in $2 \mathrm{H}_{2}+\mathrm{O}_{2}+3 \mathrm{Ar}$ at initial pressures of the order of 12 to $13 \mathrm{kPa}$. The limiting pressure increases 
Table 3. Limiting pressures, $P_{L}$ for rapid attenuation of detonation in a $50 \mathrm{~mm}$ diameter cylindrical pipe lined with two absorbing materials and corresponding detonation cell width, $W$

\begin{tabular}{lcc}
\hline Mixture & $P_{L}(\mathrm{kPa})$ & Cell width $W(\mathrm{~mm})$ \\
\hline & Wire Mesh & \\
$2 \mathrm{H}_{2}+\mathrm{O}_{2}+3 \mathrm{Ar}$ & 12 & 16 \\
$2 \mathrm{H}_{2}+\mathrm{O}_{2}+9 \mathrm{Ar}$ & 29 & 22 \\
$\mathrm{C}_{2} \mathrm{H}_{6}+3.5 \mathrm{O}_{2}+4.5 \mathrm{Ar}$ & 8 & 40 \\
$\mathrm{C}_{2} \mathrm{H}_{6}+3.5 \mathrm{O}_{2}+4.5 \mathrm{~N}_{2}$ & 22 & 32 \\
$\mathrm{C}_{3} \mathrm{H}_{8}+5 \mathrm{O}_{2}+6 \mathrm{Ar}$ & 9.3 & \\
$\mathrm{C}_{3} \mathrm{H}_{8}+5 \mathrm{O}_{2}+6 \mathrm{~N}_{2}$ & 18 & \\
\hline & Steel Wool & 18 \\
$2 \mathrm{H}_{2}+\mathrm{O}_{2}$ & 10 & \\
$2 \mathrm{H}_{2}+\mathrm{O}_{2}+3 \mathrm{Ar}$ & 13 & \\
$2 \mathrm{H}_{2}+\mathrm{O}_{2}+3 \mathrm{~N}$ & 45.2 & 20 \\
$2 \mathrm{H}_{2}+\mathrm{O}_{2}+9 \mathrm{Ar}$ & 34 & 32 \\
$\mathrm{C}_{2} \mathrm{H}_{6}+3.5 \mathrm{O}_{2}+4.5 \mathrm{Ar}$ & 9 & \\
$\mathrm{C}_{3} \mathrm{H}_{8}+5 \mathrm{O}_{2}+6 \mathrm{Ar}$ & 8 & \\
\hline
\end{tabular}

if nitrogen replaces argon as diluent, e.g. from 8 to $20 \mathrm{kPa}$ in $\mathrm{C}_{2} \mathrm{H}_{6}+3.5 \mathrm{O}_{2}$ with $50 \%$ diluent.

The overall conclusion is that steel wool is only marginally more effective in attenuating transverse waves in detonations than the woven mesh used. The results also show that mixtures with added nitrogen or whose cell size is irregular for other reasons are mitigated at greater initial pressures. There is insufficient evident however to attribute this to regularity effects alone as the dominant cell size also increases and the likelihood of mitigation must also correlate with increasing 'natural' cell size.

Acknowledgements. The study was sponsored by the National Science Foundation Committee of China (NSFC) with grant No. 19872068 and by the British Council under its Academic Link with China scheme.

\section{References}

Dupre G, Knustautus R, Lee JH (1986) Near-limit propagation of detonation in tubes, A.I.A.A., Prog Astronaut Aeronaut 106:144-259

Dupre G, Peraldi O, Lee JH, Knystautas R (1988) Propagation of detonation waves in an acoustic absorbing walled tube. AIAA Prog Astronaut Aeronaut 114:248-263

Dupre G, Peraldi O, Joannon J, Lee JH and Knustautus R (1990) Limit criterion of detonation in circular tubes, AIAA Prog Astronaut Aeronaut 133:156-169

Edwards DH (1969) A survey of recent work on the structure of detonation waves. Proc Combust Inst 12:819-828

Edwards DH, Thomas GO, Nettleton MA (1979) Diffraction of planar detonation wave at an abrupt area change J Fluid Mech 95:79-96

Edwards DH, Fearnley PJ, Thomas GO, Nettleton MA (1981) Shocks and detonations in channels with $90^{\circ}$ bends. Proc First Int Specialist Meeting on Combustion, Bordeaux, pp 431-435

Evans MW, Given FI, Richeson WE (1955) Effects of attenuating materials on detonation induction distances in gases. J Appl Phys 26:1111-1113

Fowles GR (1984) Instabilities of shock and detonation waves. Phys Fluid 27:1982-1989

Guo C, Li J (2000) Experimental investigation of acoustic absorption of detonation by absorbing materials lined wall. J Explosion and Shock Wave (in Chinese) 20(4):289-295

Manson N, Dabora EK (1993) Chronology of research on detonation waves 1920-1950. AIAA Prog Astronaut Aeronaut 153:43-39

Strehlow RA (1969) The nature of transverse waves in detonation. Astro Acta 14:539-544

Vasilév AA (1994) Near-limiting detonation in channels with porous walls. Combust Explosion Shock Waves 30(1):101106 